\title{
Measuring and mapping the emergence of the digital economy: a comparison of the market capitalization in selected countries
}

\author{
Simon C. Mueller, Alex Bakhirev, Markus Böhm, Marina Schröer, Helmut Krcmar and \\ Isabell M. Welpe
}

\begin{abstract}
Purpose - The purpose of this paper is to develop a method to quantify the digital economy using a representative measurement approach and use it to analyze the USA, Germany, the Republic of Korea and Sweden.

Design/methodology/approach - The research approach of this paper is based on a developed methodology to identify firms of the digital economy by measuring the market capitalization of selected countries in comparison over time using financial databases.

Findings - Comparing the market capitalization of the digital economy, the USA lead both in absolute as well as in relative terms. The 11 firms with the largest market capitalization are all American. For Germany, the results show that policy measures should be undertaken to ameliorate competitiveness in the field.

Research limitations/implications - This current measurement only includes public firms. An interesting avenue for future research would be to transfer the approach to investigate private firms.

Originality/value - Previous research has focused on comparing information and communication technologies adoption and infrastructure as well as innovation hubs between countries. The authors are not aware of any paper to date which has compared market capitalization in the digital economy between countries using a representative sample. This paper offers a research approach to measure and compare the digital economy between countries. The methodology could be applied to other countries which seek to benchmark their performance and derive policy measures to be able to compete with jurisdictions leading in the digital economy.
\end{abstract}

Keywords Innovation, Public policy, Digital economy, Digital business, Internet economy,

Market capitalization

Paper type Research paper

\section{Introduction[1]}

Mobile devices and digital business models have found far-reaching economic and social application during the past decade at a pace unparalleled in history. By bringing a full experience of the internet and all of its use-cases also on mobile devices, the iPhone could rapidly gain market share (West and Mace, 2010). In July 2005, the small company Android Inc. was acquired by Google Inc. for an estimated price of just \$50mn. Meanwhile, Android has become the leading operating system for mobile devices, and not even ten years later, 1.6 billion people worldwide use a smartphone with the Android operating system (Statista, 2015). The impact can be seen everywhere around the globe just by the number of people using their smartphone at a given place and time. Mobile internet and, hence the opportunity to participate quasi-instantaneously in existing markets, has spread worldwide at an extremely high speed, which very few observers expected.
(Information about the authors can be found at the end of this article.)

(C) Simon C. Mueller, Alex Bakhirev, Markus Böhm, Marina Schröer, Helmut Krcmar and Isabell M. Welpe. Published by Emerald Publishing Limited. This article is published under the Creative Commons Attribution (CC BY 4.0) licence. Anyone may reproduce, distribute, translate and create derivative works of this article (for both commercial and

non-commercial purposes), subject to full attribution to the original publication and authors. The full terms of this licence may be seen at: http://creativecommons.org/ licences/by/4.0/legalcode

Received 20 January 2017 Revised 13 March 2017 Accepted 14 March 2017 
However, Weber et al. (2011) noted a lack of innovations from Europe over the USA and Asian countries. This notion persists and receives increased awareness by policy-makers. Angela Merkel, for example, pointed out at the World Economic Forum 2015 in Davos that "A sober look at the role of Europe in the field of digitization, the role of the USA and the role of some Asian countries shows however: we rather have to catch up than that we could claim to be at the top [transl. from German]" (Merkel, 2015). The success, particularly of Google, has also raised suspicion of a violation of competition regulations. Indeed, the European Commission has opened an anti-trust case (Europäische Kommission, 2015).

For business-to-customer markets, such as mobile operating systems or smartphones, the US dominance is rather obvious. However, the overall picture of the digital economy, including business-to-business firms, is non-obvious and calls for reliable measurement. Only a precise and reproducible way to measure the digital economy allows researchers and policy-makers to assess the status quo and identify the need for action. Therefore, the exact performance remains to be quantified, as policy-makers need reliable studies for their decision-making. How the evolution of a digital economy of a given country can be quantified in an international comparison is, therefore, the research question which this paper seeks to address.

\section{Theoretical background}

Since Tapscott's (1996) book, the term "digital economy" has received increasing attention. The term first diffused during the turn of the millennium along with the spread of the internet. It has gained further popularity following the introduction and diffusion of smartphones since 2007. Notably, also the OECD has embraced the issue and accompanying policy questions. It is publishing a broad variety of reports, among others the "Digital Economy Papers" as well as the "Digital Economy Outlooks". The OECD (2014) has also issued a comprehensive set of indicators for comparisons between countries in their report "Measuring the digital economy". These indicators are predominantly about the infrastructure, societal adoption and investments in information and communication technologies (ICTs). In fact, research on the adoption of ICT started decades ago, along with efforts to measure the "digital divide" (Corrocher and Ordanini, 2002; Selwyn, 2004) within and between nations. Also, Dutta et al. (2015) have measured and compared ICT-related factors and calculated a "network readiness", as well as outcome factors such as the number of ICT-related patents of countries. Dutta et al. (2015, p. 8) rank Sweden at the 3rd position, the USA 7th, the Republic of Korea 12th and Germany 13th regarding network readiness. Desruelle and Stančík (2014) compared "Value Added" and "Business Expenses in R\&D (BERD)", as well as ICT priority patents, between the EU, USA, Japan, China, Korea and Taiwan and found a leading position by the USA.

Katz and Koutroumpis (2013) have investigated the link between digitization (i.e. the process of an increased use of digital communication technologies in the society) and welfare. Katz and Koutroumpis (2013, p. 315) measured digitization using an index based on "affordability", "infrastructure reliability", "network access", "capacity", "usage" and "human capital". They used descriptive and correlational statistics to investigate and describe the effect on welfare, as measured by the gross domestic product (GDP) per capita, the life satisfaction and the Gallup Thriving Index. Nevertheless, the OECD (2014, p. 15) has identified several areas with a need for future research and noted that researchers should "Improve the measurement of ICT investment and its link to macroeconomic performance".

Macroeconomic performance in ICT has been investigated already before the diffusion of social, mobile, analytics and cloud (SMAC) technologies as part of the digital revolution. Already a decade ago, the success of software firms has attracted the interest of researchers and policy-makers to investigate and implement factors contributing to the successful establishment of clusters of such companies (Carmel, 2003). The rapid diffusion 
of mobile technologies, which was predominantly driven by a few players, has motivated further research in the area. This has also been because of previous theoretical work regarding the competitive dynamics in the internet, which has highlighted the role of bundling (Bakos and Brynjolfsson, 2000) and network externalities (Katz and Shapiro, 1985). It could be shown that these effects give advantages particularly to large players. Zhu and lansiti (2012) could demonstrate that new entrants can fail to enter platform-based markets even if their product is better than incumbents. Kuchinke and Vidal (2016, p. 1) theoretically describe "winner takes it all" effects and provide anecdotic evidence for Amazon, Google and Facebook. Garcia-Swartz and Garcia-Vicente (2015) empirically investigated the Apple app store as a two-sided market and could demonstrate network effects. Engel (2015) identified characteristic components and behaviors in the Silicon Valley which stimulate the local ecosystem and lead to economic growth and examined the application of these in other regions of the world.

A study of Curwen et al. (2015) examined the presence of European telecommunication, media and technology companies within successive FT500 lists of the world's largest companies measured by market capitalization. They pointed out a limited presence of European companies. Simon (2016a) recently analyzed a sample of 23 firms with high market capitalization active in mobile technologies and concluded a competitive disadvantage of Europe in the field (Simon, 2016c, 2016b). The authors, however, note that the work was carried out "without aiming to build a statistically representative sample" (Simon, 2016a, p. 2), thus limiting the generalizability of the results.

Particularly, research building on a representative sample of firms in selected countries is necessary to allow conclusions for policy-makers. There are several reports which compare existing innovation centers (Table I). One of these has been conducted by Compass (2015), which has published "The Global Startup Ecosystem Ranking 2015". It examines and compares internationally important formation centers like the Silicon Valley, Tel Aviv, Berlin, London or Amsterdam. The review is based on factors such as "performance, funding, market reach, talent" and "startup experience". A similar ranking of global start-up ecosystems has been published by SparkLabs Global Ventures (2016). In its list of the ten leading international development centers in 2016, Berlin, for example, is ranked tenth. The Silicon Valley leads the list. All criteria taken together, Stockholm comes in second and Seoul seventh. The evaluation was made on the basis of hard and soft factors such as the "engineering talent, entrepreneurs/mentors, technical infrastructure, funding ecosystem \& exits, startup culture, legal \& policy infrastructure, economic foundation, government policies \& programs" (SparkLabs Global Ventures, 2016, p. 26). Recent studies, such as by Guzman and Stern (2015b), have looked at the Silicon Valley in detail. While this has happened without a specific industry focus, the location of many prominent firms of the digital economy renders the research relevant in our empirical context.

Despite the research mentioned in the paragraphs above, which compared ICT adoption between countries, the link between digitization and welfare, as well as the relative performance of innovation hubs, the evolution of the digital economy as a function of time and country using a representative sample remains to be measured. This is a much-pressing research gap, which we seek to close.

\section{Methods}

To measure the evolution of the digital economy, multiple approaches are conceivable. The most accurate approach would certainly be to assess manually whether individual business models fit within the general notion of the digital economy. This method is, however, not feasible within a reasonable time.

Similar to innovation research using patent data (Schmoch, 2008; Lanzi et al., 2011; Mueller et al., 2015), relying on a classification system has the advantage of reproducibility and 
Study

Compass (2015)

SparkLabs Global Ventures (2016)

Dutta et al. (2015)

International Telecommunication Union (2014)

Desruelle and Stančík (2014)

OECD (2014)

OECD (2013a)

Bundesministerium für Wirtschaft and Energie (2015)

Katz and Koutroumpis (2013)

Curwen et al. (2015)

Simon (2016a)

\section{Important variables}

Performance, funding, market reach, talent start-up experience

Deal count and investment size by continent

Network readiness index composed of ICT access variables

ICT development index (IDI), consisting of many ICT indicators

Value added, BERD, BERD intensity and labor productivity

Numerous ICT variables

Value added across sectors, information sector revenues

Infrastructure, ICT-revenues, utilization, market, global competitiveness

Composed index of ICT access and cost variables

Number of telecommunication, media and technology (TMT) firms within the Financial Times 500 list

Market capitalization
Contribution and limitation

Detailed overview on size, importance and trajectory of start-up hubs. Only restricted on hubs and not representative

Overview on size and importance of start-up hubs. Only restricted on hubs and not representative

A comprehensive collection of indicators on ICT use, diffusion and costs for the majority of countries worldwide. Little insight on top players

A comprehensive collection of indicators on ICT use, diffusion and costs for the majority of countries worldwide. Little insight on top players

Reliable insight from a great diversity of data sources on the investigated variables. No insight on top players and geographic distribution in selected countries

A comprehensive collection of indicators on ICT use, diffusion and costs for OECD countries, no identification of significant players of strategic importance

Detailed revenue information in the information sector. No insight regarding top players and geographic distribution in selected countries Compact ranking of countries. Only information about status quo, not on evolution over time

An empirical investigation on the link between digitization and social welfare. No variables on firm size or investments Insight into most important telecommunications, media and technology players in Europe; however, the development of number over time has significant limitations Qualitative insight into "unicorns"; however, no representative sample selection

reliability of the selection compared to other approaches, such as keyword-based search strategies for example.

Using industrial classification systems, it is indeed straightforward to identify established ICT firms, as the respective industrial sector classification has existed for several decades. However, this approach also has limitations. Nathan and Rosso (2015, p. 1714) used a big proprietary data set for the UK and found that ICT production is around 42 per cent larger than their SIC-based estimates. Including additional SIC codes to circumvent this limitation can, however, also lead to too many firms, as Nathan and Rosso (2015, p. 1715) write by referring to the OECD (2013b): "SICs can be too broad to describe new industries". The North American Industrial Classification System (NAICS) is intended to replace the SIC system. In fact, the 2002 version incorporated significant changes in the classification of the "Information Sector" (Monfardini et al., 2012, p. 14).

The most recent version of 2012 includes several codes which are relevant to the new internet economy (Table II). As the 2012 revision is comparably new and supported by the most important data providers such as Thomson Reuters, Bloomberg and Bureau van Dijk, it was the system of choice. 
Table II Internet economy relevant codes in the NAICS 2012 classification system

\begin{tabular}{ll} 
Code & Description \\
\hline 454111 & Electronic shopping \\
454112 & Electronic auctions \\
454113 & Mail-order houses \\
518210 & Data processing, hosting and related services \\
519130 & Internet publishing and broadcasting and web search portals \\
541511 & Custom computer programming services \\
541512 & Computer systems design services \\
541810 & Advertising agencies \\
Source: NAICS Association (2016) &
\end{tabular}

To investigate the digital economy, it is important to use a precise definition of the term. We used the definition by the German Federal Ministry for Economic Affairs and Energy (2014), which defines the digital economy within the German industrial classification system "Wirtschaftszweig" (WZ). According to the ministry, the digital economy consists of the traditional ICT sector as well as the internet economy.

We then used the concordance tables between WZ and the International Standard Industrial Classification (ISIC) published by Federal Statistical Office of Germany (2008) for translation into the ISIC. From there, we used the concordance tables by the United Nations (2008) for translation into the NAICS. This resulted in a set of 34 NAICS codes.

As many firm database providers still rely on the SIC, we translated the resulting set of NAICS back to SIC using tables provided by the NAICS Association (2016), with which we arrived at $38 \mathrm{SIC}$ codes.

We chose the final set of firms by the union of the sets of NAICS and SIC codes. We then derived all tickers for companies which had a NAICS or SIC code contained in our set and were primarily located in the countries selected for our analysis. Next to Germany, the strongest economy within the European Union, we chose the USA for comparison, as it has the strongest economy by GDP worldwide (International Monetary Fund, 2016). We also chose the Republic of Korea, as it is the country of Samsung, the smartphone manufacturer with the greatest market share worldwide (Statista and IDC, 2016). Furthermore, we chose Sweden as a European country of comparison, as Stockholm has the highest per capita concentration of technology companies with a rating of more than $\$ 1$ bn (Forbes, 2015).

To gain insight into the spatial distribution, we downloaded data for Germany, the USA, the Republic of Korea and Sweden in the summer of 2015. Our approach resulted in a set of around 2,690 firms, for which we retrieved the market capitalization and addresses. For additional insights on the evolution over time, we downloaded a second data set at a different date, also retrieving values for the past calendar years. This sample included 2,714 firms.

We relied on the evolution of the market capitalization as the benchmark between the countries. Profit as a measurement of the digital economy has the disadvantage that some major firms such as Amazon follow a strategy of reinvesting all profits for growth (Evans, 2014), which would underestimate the value creation of the digital economy. Compared to a measurement by revenue, the market capitalization has the advantage that the market also factors in foreseeable developments of the future (Figure 1).

\section{Results}

To gain more detailed insight into the digital economy, we divided the results between traditional ICT firms and the internet economy. The diagrams display the top three as well as the rest of both categories. We also analyzed the geospatial location, as the strength of the local ecosystems has frequently been mentioned in the literature as one of the key 


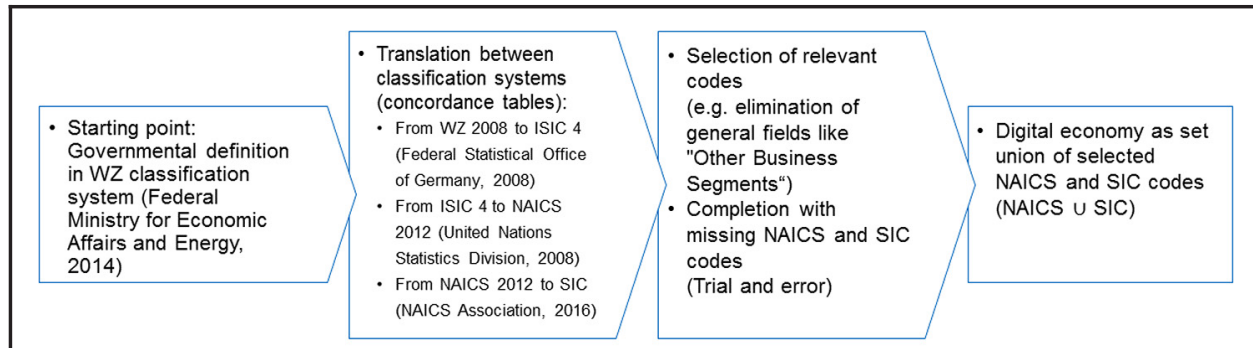

Source: Adapted from Müller et al. (2016)

factors for innovation. We used the ZIP Code for the analysis, as it has also been used in previous research to rank areas by entrepreneurial quality in selected regions such as the Route 128 (Guzman and Stern, 2015a) and the Silicon Valley (Guzman and Stern, 2015b).

\subsection{The USA}

Figure 3 shows the market capitalization of US firms over time. It is remarkable that two of the biggest companies are both larger than all German enterprises in the sample together. The most valuable firm up to the last data point has been Apple. It is furthermore remarkable that Google (since the retrieval of our data renamed to Alphabet), as a company with an IPO after 2001, is among the largest firms in the USA (and therefore worldwide) in the digital economy. This rapid growth continued: In 2016, in fact, Apple and Alphabet had a close race regarding the highest market capitalization, and Alphabet managed to be ahead of Apple twice (Solomon, 2016).

However, Figure 2(a) shows that it is not only the Silicon Valley which ensures the lead of the USA but also Seattle, having Amazon and Microsoft in the metropolitan area, as well as New York City, contributes to a strong digital economy in the USA. Figure 2(b) gives an overview of the ten leading districts by market capitalization in the USA. For aggregation, we summarized the areas by removing the last digit of the postal code. The two districts with the highest market cap as well as five more in the top ten are in California. All of the Californian areas except for $9152^{*}$ (receiving its high ranking because of Walt Disney in 91522 Burbank) are located in the San Francisco Bay area (Figure 3).

Figure 2 (a) Regional distribution of the market capitalization in the digital economy in the USA [adapted from Müller et al. (2016)]; and (b) Ten leading districts by market capitalization

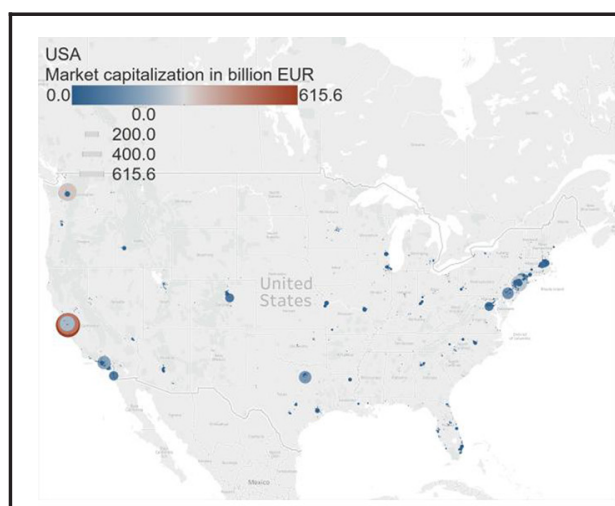

(a)

\begin{tabular}{clcc} 
ZIP & \multicolumn{1}{c}{ State } & $\begin{array}{c}\text { Market } \\
\text { Cap. }(\text { Bn. } €)\end{array}$ & $\begin{array}{c}\text { No. of } \\
\text { companies }\end{array}$ \\
\hline 9501* & California & 615.6 & 2 \\
9404* & California & 480.0 & 12 \\
9805* & Washington & 341.4 & 4 \\
1003* & New York & 266.1 & 13 \\
9402* & California & 242.8 & 7 \\
9810* & Washington & 234.7 & 8 \\
9513* & California & 197.4 & 41 \\
9406* & California & 196.4 & 21 \\
$9505^{*}$ & California & 193.6 & 19 \\
$9152 *$ & California & 187.3 & 1
\end{tabular}

(b) 


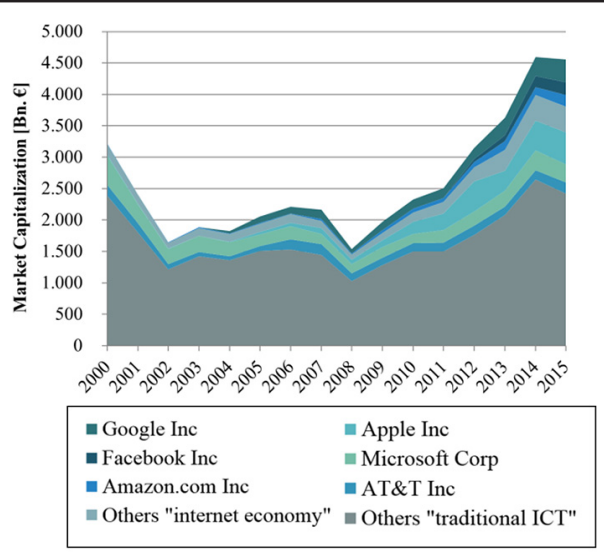

Source: Müller et al. (2016, p. 25)

\subsection{Germany}

Figure 5 shows the market capitalization of the German companies within the selection. The three biggest corporations are Deutsche Telekom AG, SAP SE and Siemens AG. The three largest of the internet economy are given by United Internet AG, Zalando SE and the Axel Springer SE. Unlike in the USA, these firms, however, do not reach the size of the traditional players from ICT.

United Internet AG is active in web hosting and internet service provider (ISP). Zalando SE operates a large online store business for clothes and other fashion items. Axel Springer SE not only is a publisher of leading newspapers in Germany but also has significant digital media activities, which among others relate to the journals it is publishing.

Figure 4(a) shows Germany and the market capitalization in different areas. The ten leading districts are shown in Figure 4(b). Especially Munich and the suburbs around it (Unterfoehring and Neubiberg) host companies with a large market capitalization. In addition, big companies also have their headquarters in Walldorf and Bonn, whereas the highest ranked districts of Berlin are at the ninth and tenth place. Because of the increased

\section{Figure 4 (a) Regional distribution of the market capitalization in the digital economy in Germany [adapted from Müller et al. (2016)]; and (b) Top ten districts by market capitalization}

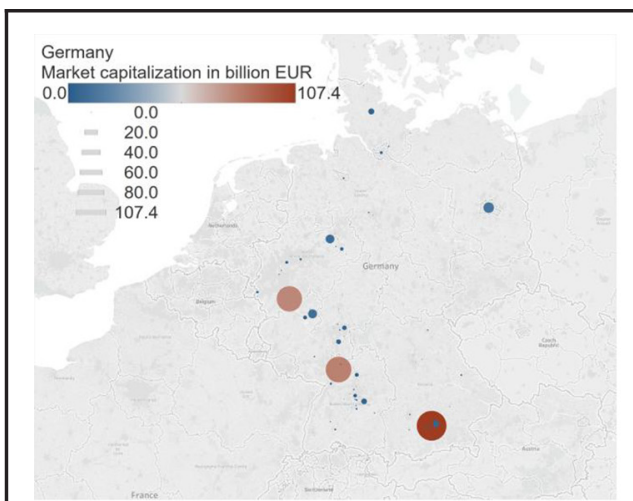

(a)

\begin{tabular}{clcc} 
ZIP & \multicolumn{1}{c}{ City } & $\begin{array}{c}\text { Market } \\
\text { Cap. }(\text { Bn. } € \text { ) }\end{array}$ & $\begin{array}{c}\text { No. of } \\
\text { companies }\end{array}$ \\
\hline $8033^{*}$ & Muenchen & 86.5 & 5 \\
6919* & Walldorf & 80.3 & 2 \\
531 * $^{*}$ & Bonn & 77.8 & 1 \\
$8577 *$ & Unterfoehring & 27.6 & 3 \\
$8099^{*}$ & Muenchen & 17.1 & 1 \\
$8557 *$ & Neubiberg & 11.4 & 1 \\
$5641 *$ & Montabaur & 9.4 & 1 \\
3331* & Guetersloh & 8.9 & 1 \\
$1024 *$ & Berlin & 7.8 & 1 \\
$1088^{*}$ & Berlin & 5.0 & 1
\end{tabular}

(b) 
number of venture capital investments and exits, Berlin is ranked first regarding relative growth by Compass (2015). In their overall ranking, Berlin occupies the ninth place worldwide. While several studies note the highest density of new ventures in Berlin, the market capitalization does not reflect the leading position of Berlin in the digital economy. Despite the upward trend, the role of Berlin compared to the pioneering Silicon Valley is negligible, in particular with respect to the market capitalization (Figure 5).

\subsection{The Republic of Korea}

The corporations of the Republic of Korea are shown in Figure 7. It is a striking feature of the Korean digital economy that Samsung Electronics Co comprises roughly one-third of the total market capitalization. Samsung also played a crucial role in the creation of Naver Corp, which started as an in-house venture of Samsung (Economist, 2014). Nowadays, Naver has a market share of nearly 80 per cent (Economist, 2014) and is the most frequently visited website in Korea (Alexa Internet, 2015). Recent research by Ji et al. (2016) found that domestic search engines may lead to growth in the size of the country's digital advertising market.

Daum Kakao, which since the acquisition of our data has been renamed to Kakao, resulted out of the merger of Daum Communications and Kakao (Kakao Corp, 2016). Next to other activities, an important product is Kakao Talk, a messaging app which is installed on more than 95 per cent of the smartphones in Korea (Russel, 2015). Another prominent company is NC Soft Corp, which develops massively multiplayer online games (Crunchbase, 2016). SK Hynix, a manufacturer of memory chips (SK Hynix, 2016), and SK Telecom both belong to the SK Group (SK, 2016).

Traditionally, Korea's policy-makers have steered the ICT sector rather tightly (Larson and Park, 2014). Also currently, policy-makers try to shape the entrepreneurial ecosystem. Here, the concept for the remote island Jeju is also worthwhile noticing. The market capitalization there is given by Kakao, which has its headquarter there. The Korean government seeks to strengthen the entrepreneurship ecosystem on the island building up on the initial success (Gruppta, 2016).

Figures 6(a) and (b) give an overview of the administration districts with the highest market capitalizations. All areas listed in Figure 6(b) are in the greater Seoul area (Figure 7).

Figure 5 Market capitalization of German companies in the digital economy

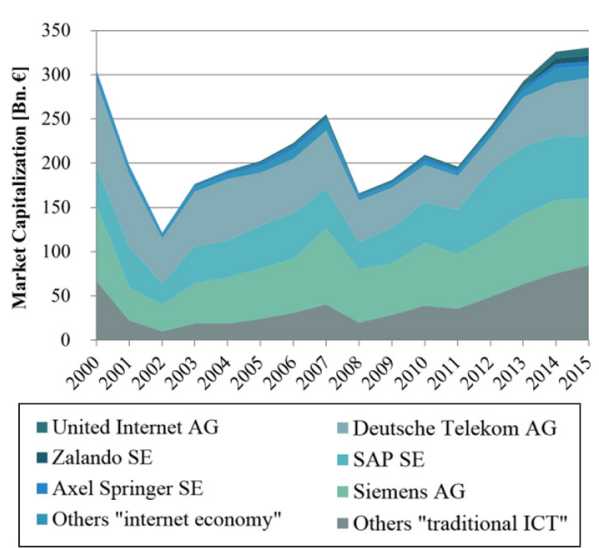

Source: Müller et al. (2016, p. 25) 
Figure 6 (a) Regional distribution of the market capitalization in the digital economy in the Republic of Korea [adapted from Müller et al. (2016)]; and (b) Top ten administration districts by market capitalization

\begin{tabular}{|c|c|c|c|c|}
\hline \multirow{2}{*}{$\begin{array}{l}\text { Republic of Korea } \\
\text { Market capitalization in billion EUR } \\
0.0 \\
140.4\end{array}$} & ZIP & Administration & $\begin{array}{l}\text { Marke } \\
\text { t Cap. } \\
\text { (Bn. €) }\end{array}$ & $\begin{array}{c}\text { No. of } \\
\text { companie } \\
\text { s }\end{array}$ \\
\hline & $1667 *$ & Suwonsiyeongtonggu & 140.0 & 4 \\
\hline $\begin{array}{r}50.0 \\
=100.0\end{array}$ & $1739 *$ & Icheon-si & 21.2 & 1 \\
\hline-140.4 & 0733* & Yeongdeungpo-gu & 19.8 & 3 \\
\hline$a^{2}=$ & $0561 *$ & Songpa-gu & 17.9 & 2 \\
\hline & 0453* & Jung-gu & 16.2 & 2 \\
\hline & $1356^{*}$ & $\begin{array}{l}\text { Seongnamsibundangg } \\
\mathrm{u}\end{array}$ & 13.7 & 2 \\
\hline & $0318^{*}$ & Jongno-gu & 10.5 & 1 \\
\hline & $1352 *$ & $\begin{array}{l}\text { Seongnamsibundangg } \\
\mathrm{u}\end{array}$ & 6.8 & 38 \\
\hline & $1360^{*}$ & $\begin{array}{l}\text { Seongnamsibundangg } \\
\mathrm{u}\end{array}$ & 6.3 & 3 \\
\hline (a) & $0616^{*}$ & $\begin{array}{l}\text { Gangnam-gu } \\
\\
\text { (b) }\end{array}$ & 6.0 & 7 \\
\hline
\end{tabular}

Figure 7 Market capitalization of South Korean companies in the digital economy

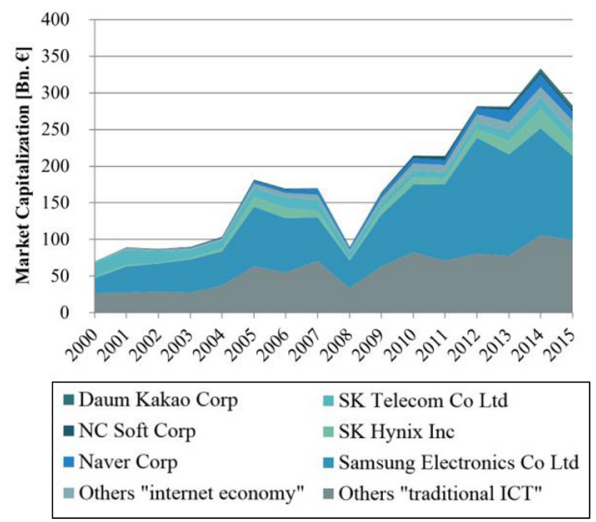

Source: Müller et al. (2016, p. 26)

\subsection{Sweden}

Figure 9 shows the development of the market capitalization of the Swedish digital economy over time. A significant fraction of the market capitalization is because of Ericsson. Assa Abloy's main activities relate to the provision of door locks (Bureau van Dijk Electronic Publishing, 2016) and was included in our sample because of the SIC code "3669 - Communications Equipment, nec".

Regarding the firms active in the internet economy, the top three are given by Loomis $A B$, Evolution Gaming Group publ $\mathrm{AB}$ and $\mathrm{HiQ}$ International $\mathrm{AB}$. Loomis is active in the area of cash management, automated teller machines and related technical services (Bureau van Dijk Electronic Publishing, 2016). While it is not immediately apparent that it is a firm of the digital economy, it was included in our sample, as its NAICS code in ThomsonONE is "518210 - Data Processing, Hosting, and Related Services". The Evolution Gaming group offers solutions for online games, such as live casinos (Bureau van Dijk Electronic Publishing, 2016). The third largest firm relating to the internet economy in Sweden is HiQ 
International, an IT consultancy. Regarding the regional distribution, much of the Swedish digital economy is concentrated in Stockholm. Spotify, the popular music-streaming service, was not included in our sample, as it did not have an IPO to date.

Figures $8(a)$ and (b) show the locations of the firms with the highest market capitalization within Sweden. Six of the ten leading districts are located in the Stockholm area, making it the most important area in Sweden (Figure 9).

\subsection{Cross-country comparison}

Table III shows the 20 largest firms by market capitalization in our sample. The top 11 companies are all from the USA. It is remarkable that two of the largest companies had their IPO after 2000 and are, therefore, comparably young. The first non-US on place 12 is Samsung Electronics. The largest German companies are ranked at position 16, 17 and 18.

A similar impression can be obtained by looking at the biggest IPOs with the 15 highest market capitalizations at the day of the IPO since 2001. While older companies such as Twenty-First Century Fox and Time Warner Cable are represented, it is noticeable that

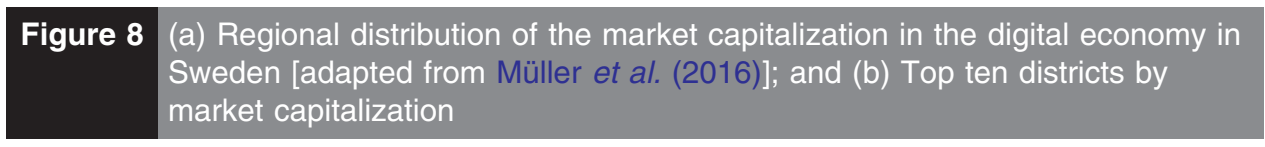

\begin{tabular}{|c|c|c|c|c|}
\hline \multirow{11}{*}{$\begin{array}{l}\text { Sweden } \\
\text { Market capitalization in billion EUR } \\
\begin{aligned} & 0.0 \\
& 0.0 \\
&= \\
&= 20.0 \\
&= 40.0 \\
& 57.8\end{aligned}\end{array}$} & ZIP & City & $\begin{array}{c}\text { Market } \\
\text { Cap. } \\
\text { (Bn. €) }\end{array}$ & $\begin{array}{c}\text { No. of } \\
\text { Companies }\end{array}$ \\
\hline & $1648 *$ & Kista & 31.9 & 1 \\
\hline & $1066^{*}$ & Stockholm & 24.1 & 1 \\
\hline & $1072 *$ & Stockholm & 20.7 & 1 \\
\hline & $1031^{*}$ & Stockholm & 4.3 & 1 \\
\hline & $1113 *$ & Stockholm & 3.7 & 5 \\
\hline & $2236^{*}$ & Lund & 2.6 & 2 \\
\hline & $1013 *$ & Solna & 1.9 & 1 \\
\hline & $1042 *$ & Stockholm & 1.7 & 1 \\
\hline & $5833 *$ & Linkoping & 1.2 & 2 \\
\hline & 4111* & Goteborg & 1.2 & 1 \\
\hline (a) & & & (b) & \\
\hline
\end{tabular}

\section{Figure 9 Market capitalization of Swedish companies in the digital economy}

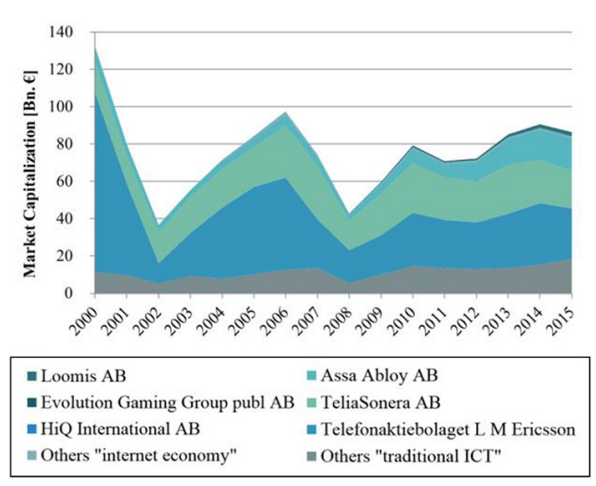

Source: Müller et al. (2016, p. 26) 
Table III Companies of the digital economy in USA, SWE, DEU and KOR with the largest market capitalization

\begin{tabular}{|c|c|c|c|c|}
\hline Company & Country & Market capitalization [Bn. $€]$ & Date IPO & Market capitalization day of IPO [Bn. €] \\
\hline Apple Inc & USA & 616 & 12.12.1980 & 1.06 \\
\hline Google Inc & USA & 407 & 19.08.2004 & 22.0 \\
\hline Microsoft Corp & USA & 341 & 13.03.1986 & 0.691 \\
\hline Facebook Inc & USA & 241 & 18.05 .2012 & 64.3 \\
\hline Amazon.com Inc & USA & 228 & 15.05 .1997 & 0.486 \\
\hline Walt Disney Co & USA & 187 & 12.11 .1957 & NA \\
\hline Verizon Communications Inc & USA & 174 & 21.11.1983 & 7.58 \\
\hline AT\&T Inc & USA & 164 & 21.11 .1983 & 6.65 \\
\hline Oracle Corp & USA & 157 & 12.03 .1986 & 0.041 \\
\hline Comcast Corp & USA & 144 & June 1972 & NA \\
\hline IBM Corp & USA & 142 & 11.11 .1915 & NA \\
\hline Samsung Electronics Co Ltd & KOR & 136 & 02.07 .1984 & 0.242 \\
\hline Cisco Systems Inc & USA & 131 & 16.02.1990 & 0.173 \\
\hline Intel Corp & USA & 126 & October 1971 & NA \\
\hline Qualcomm Inc & USA & 92 & 13.12.1991 & 0.261 \\
\hline Siemens AG & DEU & 86 & 01.07 .1991 & 17.1 \\
\hline SAP SE & DEU & 80 & 18.12 .1996 & 6.36 \\
\hline Deutsche Telekom AG & DEU & 78 & 15.11 .1996 & 29.6 \\
\hline Twenty-First Century Fox Inc & USA & 64 & 03.11 .2004 & 45.7 \\
\hline Hewlett-Packard Co & USA & 49 & 06.11 .1957 & NA \\
\hline
\end{tabular}

many very young companies, such as Facebook, Google, Twitter and Linkedln, have successfully debuted with large market capitalizations at the stock exchanges.

We also plotted the market capitalization in the investigated countries, which can be seen in Figure 10.

Of course, the market cap of these companies is also susceptible to the overall stock market climate, which can be seen after the bursting of the .com-bubble and the reduction of the capitalization after 2007. It is nevertheless remarkable that the overall increase in market capitalization in the digital economy - which more than doubled since 2008 happened in the USA. The strength of the Silicon Valley, with the top districts housing a total of close to 2 trillion in market capitalization, is unparalleled. Compared to the district $8033^{*}$ in Munich, Germany 9501* in California, the USA has a seven times higher market capitalization. Moreover, the USA not only leads in absolute but also in relative terms. This

Figure 10 (a) Country comparison of market capitalizations [adapted from Müller et al. (2016, p. 27)]; (b) Country comparison of relative market capitalizations

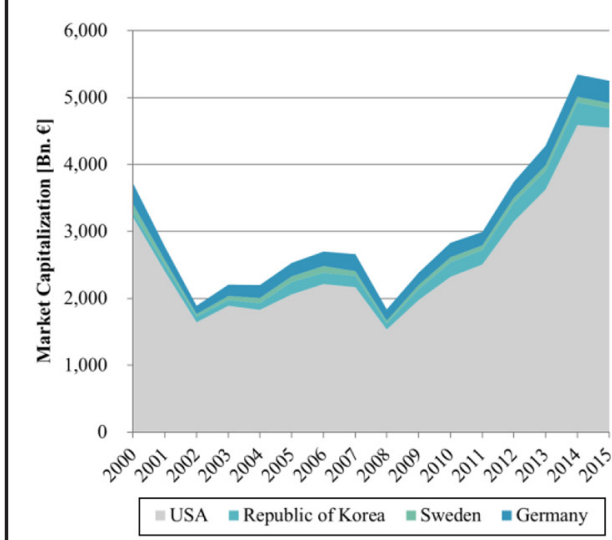

(a)

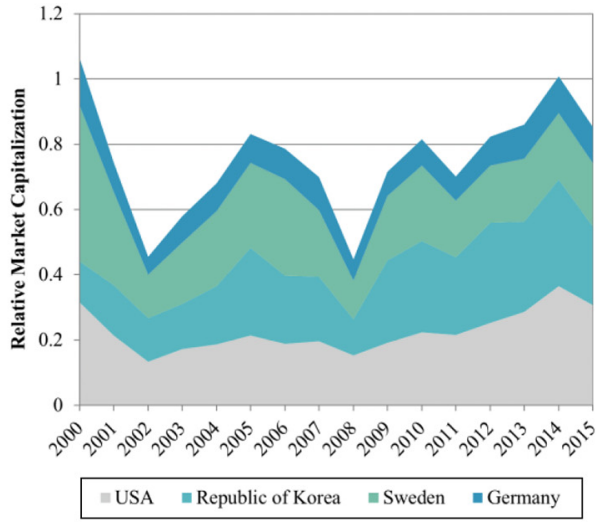

(b) 
can be seen in Figure 10(b), which shows the market capitalization divided by the GDP. In 2015, the market capitalization of the digital economy relative to the GDP reached 0.31 in the USA. Between 2008 and 2015, the ratio "digital economy market capitalization divided by the GDP" grew in all countries. In the USA from 0.15 to 0.31 , in the Republic of Korea from 0.11 to 0.24 , in Sweden from 0.12 to 0.20 and in Germany from 0.06 to 0.11 .

\section{Conclusion and discussion}

Our study shows that the impression of dominance by the USA in the digital economy also holds true when using a standardized and reproducible measurement approach. Because of this, policy-makers in other countries, particularly in Germany, should be alarmed by the findings. Among the investigated countries, only in the USA, firms established after the year 2000 could grow and reach market capitalizations of more than $\$ 100 \mathrm{bn}$. With Samsung, South Korea has at least one significant player in the field. While this is positive, the Korean digital economy is also highly dependent on the performance of Samsung, which is not optimal from a risk management perspective. While the USA is driving the digital transformation, two points remain worthwhile to note: First, also areas other than the Silicon Valley hold great potential to become a breeding ground for successful ventures, as well-established players can also be found in other places. Second - unlike in Sweden or Germany - the total market capitalization in the investigated sector is significantly above the levels of the year 2000, before the .com-bubble burst. Consequently, further research regarding valuation methods is, therefore, needed and the risk of overvaluation has to be closely monitored.

In Germany, the portfolio of large firms only consists of rather old companies with a long tradition. New players, such as Rocket Internet SE (which during the past 12 months has rather been shrinking) from Berlin, do not even reach the top three. Other studies have found that Berlin has the highest number of new ventures in Germany. However, this is not yet visible in the market capitalization of the digital sector, which consists mainly of the three strong traditional players. A possible policy strategy to replicate the ecosystem of the Silicon Valley would, thus, be to increase the colocation of ventures and established market capital, either by supporting the growth of already existing ventures in Berlin and Hamburg or by increasing the number of ventures around the existing top players. After the decline of Ericsson following the burst of the .com-bubble, Sweden lacks a strong player with a high market capitalization but otherwise performs well with respect to its size.

Regarding the large international differences, some have speculated that also cultural factors could have played a role. A "fearless culture" (Stewart, 2015) has been mentioned as a helping factor in the development of the US tech companies. Further studies should look at which factors contributed to the creation of domestic players for search engines in the Republic of Korea, which for example did not happen in Germany or Sweden.

Besides cultural factors, the difference in the availability of venture capital financing has been mentioned. The three largest US internet companies - like many others - relied on venture capital during their growth phase. There are, however, considerable differences in the proportion of capital available for seed funding and subsequent stages of start-up financing. This is also true when compared relatively to the GDP of the countries. The capital invested in seed funding in 2014 was, according to the OECD (2015), in the USA in relation to GDP eight times higher than in Germany. Investments for subsequent phases of start-up financing were even 22 times higher in the USA. The difference could, therefore, also have played a major role.

Further research should aim at quantifying the influences of path dependency, cultural factors and financing factors such as taxation of venture capital investments. A quantification could help policy-makers in countries which seek to improve their digital economy to correctly prioritize measures which use limited public funds to catch up.

PAGE 378 DIGITAL POLICY, REGULATION AND GOVERNANCE $\mid$ VOL. 19 NO. 52017 
It has been speculated whether one of the success factors of the USA in the digital economy has been the large single market which provides domestic ventures with the immediate possibility to reach 320 million customers, giving significant advantages, which subsequently amplify because of network effects. This has lead the European Commission to derive the strategy of a digital single market.

As the transition from hardware-based innovation toward software-based innovation changed the leadership from Japan to the USA (Arora et al., 2013), current positions are not cemented and could still be changed.

While our study provides the first holistic cross-country comparison on the digital economy, it is not without limitations. First, we used the primary classification of the firm to determine whether a company is selected into our sample. As many traditional companies are involved in diverse business units - some of which may not fall within the definition of the digital economy - it might be worthwhile to undertake studies including the secondary classification level. An underestimation of the digital economy in this study should, however, not be concluded, as opposite cases are also likely included in our sample.

Future studies should also analyze non-public firms. Such analysis could be carried out using global business register records databases such as Orbis by Bureau van Dijk. When measuring and mapping non-public companies of the digital economy, an alternative to the market capitalization would have to be used. Such research would be challenging because of the reduced publication duties of private firms. As prominent enterprises such as Uber and Airbnb are not publicly traded, this is an important area for future research. The combination of data on public and private businesses would allow computing "Regional Entrepreneurship Cohort Potential Indices (RECPI)" and "Entrepreneurship Quality Indices (EQI)", such as recently introduced by Guzman and Stern (2015a). The EQI allows the calculation of a probability of growth events (IPO or VC funding) within a group of companies. Guzman and Stern (2015a) further state that the RECPI allows the direct calculation of the expected number of growth events within a given group of start-ups within a defined geographical environment. In the context of the research above, this would allow evaluating the effectiveness of policies at a sub-national level.

More understanding is also needed on the influence of the digital divide on the outcome of the development of the digital economy in countries.

Finally, methodological refinements should also be developed to tackle the identification of firms operating in the digital economy. This likely also includes the need for updated classification systems. Future research should explore alternative methods for the worldwide identification of digital businesses by mining the text regarding the purpose of businesses within business registers, for example, by following the approach of Nathan and Rosso (2015) using an international data set.

\section{Funding and acknowledgement}

This paper is an adapted version of sections of our own work (Müller et al., 2016) mandated by the Commission of Experts for Research and Innovation of the Federal Republic of Germany. We are grateful for valuable suggestions and comments from Dietmar Harhoff and Alexander Cuntz. The results in this paper are our personal view and do not necessarily reflect the opinion of the Commission of Experts for Research and Innovation. Fabian Simon is acknowledged for assistance in the generation of Figures 2(b), 4(b), 6(b), 8(b) and 10. Victor Sorgenfrei and Helena Endl are acknowledged for assisting with the plotting of the maps.

\section{Note}

1. This paper is an adapted version of sections of our own work (Müller et al., 2016) mandated by the Commission of Experts for Research and Innovation of the Federal Republic of Germany. 


\section{References}

Alexa Internet (2015), "Site overview naver.com", available at: www.alexa.com/siteinfo/naver.com (accessed 11 September 2015).

Arora, A., Branstetter, L.G. and Drev, M. (2013), "Going soft: how the rise of software-based innovation led to the decline of Japan's IT industry and the resurgence of silicon valley", Review of Economics and Statistics, Vol. 95 No. 3, pp. 757-775.

Bakos, Y. and Brynjolfsson, E. (2000), "Bundling and competition on the internet", Marketing Science, Vol. 19 No. 1, pp. 63-82.

Bundesministerium für Wirtschaft und Energie (2015), "Monitoring-report Wirtschaft DIGITAL", available at: www.bmwi.de/BMWi/Redaktion/PDF/M-O/monitoring-report-wirtschaft-digital-2015, property $=$ pdf, bereich $=$ bmwi2012, sprache $=$ de, $r w b=$ true.pdf

Bureau van Dijk Electronic Publishing (2016), "Company information across the globe", available at: https://orbis.bvdinfo.com (accessed 15 June 2016).

Carmel, E. (2003), "The new software exporting nations: success factors", The Electronic Journal of Information Systems in Developing Countries, Vol. 13.

Compass (2015), The Global Startup Ecosystem Ranking, Compass, San Francisco.

Corrocher, N. and Ordanini, A. (2002), "Measuring the digital divide: a framework for the analysis of cross-country differences", Journal of Information Technology, Vol. 17 No. 1, pp. 9-19.

Crunchbase (2016), available at: www.crunchbase.com/organization/ncsoft\#/entity (accessed 16 June).

Curwen, P., Sadowski, B. and Whalley, J. (2015), "Where are the Europeans? A longitudinal analysis of the world's largest TMT companies", info, Vol. 17 No. 5, pp. 1-19.

Desruelle, P. and Stančík, J. (2014), "Characterizing and comparing the evolution of the major global economies in information and communication technologies", Telecommunications Policy, Vol. 38 No. 8, pp. 812-826.

Dutta, S., Geiger, T. and Lanvin, B. (2015), "The networked readiness index 2015: taking the pulse of the ICT revolution", The Global Information Technology Report.

Economist (2014), "Now or Naver", South Korea's internet giant, available at: www.economist.com/ news/business/21597937-home-south-koreas-biggest-web-portal-has-thrashed-yahoo-and-keptgoogle-bay-now-its (accessed 11 September 2015).

Engel, J.S. (2015), "Global clusters of innovation", California Management Review, Vol. 57 No. 2, p. 36.

Europäische Kommission (2015), "Antitrust: commission opens formal investigation against Google in relation to Android mobile operating system", available at: http://europa.eu/rapid/press-release_ MEMO-15-4782_en.htm (accessed 07 Oktober 2015).

Evans, B. (2014), "Why Amazon has no profits (And why it works)", available at: http://ben-evans.com/ benedictevans/2014/9/4/why-amazon-has-no-profits-and-why-it-works (accessed 1 June 2016).

Federal Ministry for Economic Affairs and Energy (2014), "Monitoring-Report Digitale Wirtschaft 2014: Innovationstreiber IKT", available at: www.bmwi.de/BMWi/Redaktion/PDF/Publikationen/monitoring-reportdigitale-wirtschaft-2014-langfassung, property=pdf,bereich=bmwi2012,sprache =de,rwb=true.pdf

Federal Statistical Office of Germany (2008), Klassifikation der Wirtschaftszweige, Federal Statistical Office of Germany, Wiesbaden.

Forbes (2015), "How Stockholm became a 'Unicorn Factory'”, available at: www.forbes.com/sites/ knowledgewharton/2015/11/11/how-stockholm-became-a-unicorn-factory/print/ (accessed 18 November).

Garcia-Swartz, D.D. and Garcia-Vicente, F. (2015), "Network effects on the iPhone platform: an empirical examination", Telecommunications Policy, Vol. 39 No. 10, pp. 877-895.

Gruppta, K. (2016), "South Korea's economic future depends on this bold business experiment", available at: www.forbes.com/sites/kaviguppta/2016/06/12/south-koreas-economic-future-dependson-this-bold-business-experiment/ (accessed 16 June).

Guzman, J. and Stern, S. (2015a), "Nowcasting and placecasting: entrepreneurial quality and performance", Measuring Entrepreneurial Businesses: Current Knowledge and Challenges, University of Chicago Press, Chicago. 
Guzman, J. and Stern, S. (2015b), "Where is silicon valley?", Science, Vol. 347 No. 6222, pp. 606-609. International Monetary Fund (2016), "World economic outlook database".

International Telecommunication Union (2014), "Measuring the information society report", available at: www.itu.int/en/ITU-D/Statistics/Documents/publications/mis2014/MIS2014_without_Annex_4.pdf

Ji, S.W., Choi, Y.J. and Ryu, M.H. (2016), "The economic effects of domestic search engines on the development of the online advertising market", Telecommunications Policy, Vol. 40 Nos 10/11.

Kakao Corp (2016), "History", available at: www.kakaocorp.com/en/about/history (accessed 16 June).

Katz, M.L. and Shapiro, C. (1985), "Network externalities, competition, and compatibility", The American Economic Review, Vol. 75 No. 3, pp. 424-440.

Katz, R.L. and Koutroumpis, P. (2013), "Measuring digitization: a growth and welfare multiplier", Technovation, Vol. 33 Nos 10/11, pp. 314-319.

Kuchinke, B.A. and Vidal, M. (2016), "Exclusionary strategies and the rise of winner-takes-it-all markets on the Internet", Telecommunications Policy, Vol. 40 No. 6, pp. 582-592.

Lanzi, E., Verdolini, E. and Haščičs, I. (2011), "Efficiency-improving fossil fuel technologies for electricity generation: data selection and trends", Energy Policy, Vol. 39 No. 11, pp. 7000-7014.

Larson, J.F. and Park, J. (2014), "From developmental to network state: government restructuring and ICT-led innovation in Korea", Telecommunications Policy, Vol. 38 No. 4, pp. 344-359.

Merkel, A. (2015), "Rede von Bundeskanzlerin Merkel anl. des Jahrestreffens 2015 des World Economic Forum am 22 Januar", World Economic Forum, Davos.

Monfardini, E., Probst, L., Szenci, K., Cambier, B. and Frideres, L. (2012), "Emerging industries report on the methodology for their classification and on the most active, significant and relevant new emerging industrial sectors", European Union, July, pp. 20-22.

Mueller, S.C., Sandner, P.G. and Welpe, I.M. (2015), "Monitoring innovation in electrochemical energy storage technologies: a patent-based approach", Applied Energy, Vol. 137, pp. 537-544.

Müller, S.C., Böhm, M., Schröer, M., Bakhirev, A., Baiasu, B.C., Krcmar, H. and Welpe, I. (2016), "Geschäftsmodelle in der digitalen Wirtschaft", Studien zum deutschen Innovationssystem.

NAICS Association (2016), "NAICS to SIC crosswalk", available at: www.naics.com/naicswp2014/wpcontent/uploads/2014/10/NAICS-to-SIC-Crosswalk.pdf? (accessed 1 June 2016).

Nathan, M. and Rosso, A. (2015), "Mapping digital businesses with big data: some early findings from the UK", Research Policy, Vol. 44 No. 9, pp. 1714-1733.

OECD (2013a), "Measuring the internet economy: a contribution to the research Agenda", Digital Economy Papers.

OECD (2013b), "Measuring the internet economy: a contribution to the research Agenda", OECD Digital Economy Papers, (226).

OECD (2014), Measuring the Digital Economy: A New Perspective, OECD Publishing, Paris.

OECD (2015), Entrepreneurship at a Glance, OECD Publishing, Paris, available at: http://dx.doi.org/ 10.1787/entrepreneur_aag-2015-en

Russel, J. (2015), "What is daum kakao and why did it buy path", available at: http://techcrunch.com/ 2015/05/29/what-is-daum-kakao-and-why-did-it-buy-path/ (accessed 16 June).

Schmoch, U. (2008), Concept of a Technology Classification for Country Comparisons, Fraunhofer Institute for Systems and Innovation Research, Breslauer.

Selwyn, N. (2004), "Reconsidering political and popular understandings of the digital divide", New Media \& Society, Vol. 6 No. 3, pp. 341-362.

Simon, J.P. (2016a), "How Europe missed the mobile wave", info, Vol. 18 No. 4.

Simon, J.P. (2016b), How to Catch a Unicorn: Case Studies, Institute for Prospective Technological Studies, Joint Research Centre European Commission, available at: http://publications.jrc.ec.europa. eu/repository/bitstream/JRC100720/jrc100720.pdf (accessed 6 June 2016).

Simon, J.P. (2016c), How to Catch a Unicorn: An Exploration of the Universe of Tech Companies with High Market Capitalization, Institute for Prospective Technological Studies, Joint Research Centre European 
Commission, available at: http://publications.jrc.ec.europa.eu/repository/bitstream/JRC100719/jrc100719. pdf (accessed 6 June 2016).

SK (2016), "SK makes an effort to develop new growth drives", available at: www.sk.com/About/ affiliates (accessed 16 June).

SK Hynix (2016), "Innovation from within", available at: www.skhynix.com/eng/index.jsp (accessed 16 June).

Solomon, B. (2016), "Google passed apple as the world's most valuable company (Again)", Forbes.

SparkLabs Global Ventures (2016), "Global technology trends and top ten startup hubs 2016".

Statista (2015), "Anzahl der in Gebrauch befindlichen Smartphones weltweit nach Betriebssystem im Dezember 2014 (in Millionen)", available at: http://de.statista.com/statistik/daten/studie/246004/ umfrage/weltweiter-bestand-an-smartphones-nach-betriebssystem/ (accessed 07 Oktober 2015).

Statista and IDC (2016), "Marktanteile der führenden Hersteller am Absatz von Smartphones weltweit vom 4", Quartal 2009 bis zum 1, Quartal, available at: http://de.statista.com/statistik/daten/studie/ 173056/umfrage/weltweite-marktanteile-der-smartphone-hersteller-seit-4-quartal-2009/ (accessed 14 Juni 2016).

Stewart, J.B. (2015), "A fearless culture fuels US tech giants", The New York Times, 18 June, available at: www.nytimes.com/2015/06/19/business/the-american-way-of-tech-and-europes.html?_r=0

Tapscott, D. (1996), The Digital Economy: Promise and Peril in the Age of Networked Intelligence, McGraw-Hill, New York, NY.

United Nations (2008), International Standard Industrial Classification of All Economic Activities (ISIC), Rev. 4, United Nations, New York, NY.

Weber, A., Haas, M. and Scuka, D. (2011), "Mobile service innovation: a European failure", Telecommunications Policy, Vol. 35 No. 5, pp. 469-480.

West, J. and Mace, M. (2010), "Browsing as the killer app: explaining the rapid success of Apple's iPhone”, Telecommunications Policy, Vol. 34 No. 5, pp. 270-286.

Zhu, F. and lansiti, M. (2012), "Entry into platform-based markets", Strategic Management Journal, Vol. 33 No. 1, pp. 88-106.

\section{Author Affiliations}

Simon C. Mueller is Research Associate at the TUM School of Management, Technical University of Munich, Munich, Germany.

Alex Bakhirev is based at the TUM School of Management, Technical University of Munich, Munich, Germany.

Markus Böhm is Research Group Leader at the Chair for Information Systems, Department of Informatics at Technical University of Munich (TUM), Munich Germany.

Marina Schröer is based at the TUM School of Management, Technical University of Munich, Munich, Germany.

Helmut Krcmar is Professor and Chair for Information Systems at the Department of Informatics at the Technical University of Munich (TUM), Munich, Germany.

Isabell M. Welpe is Professor and Chair for Strategy and Organization at the TUM School of Management at the Technical University of Munich (TUM), Munich, Germany.

\section{Corresponding author}

Simon C. Mueller can be contacted at: simon.mueller@tum.de

For instructions on how to order reprints of this article, please visit our website: www.emeraldgrouppublishing.com/licensing/reprints.htm

Or contact us for further details: permissions@emeraldinsight.com 